\title{
Determination of phthalate esters in children's toys
}

- Tran Thi Kieu Anh

- Luong Trong Ton

- Tran Ngoc Hoa

- Pham Minh Trang

Ho Chi Minh City University of Technology, VNU-HCM

(Manuscript Received on June 10th, 2016, Manuscript Revised August 12th, 2016)

\begin{abstract}
$A$ validated analytical method for the relative standard deviation (\%RSD) were from determination of phthalates (DBP, BBP, DEHP, DNOP, DINP and DIDP) in plastics was $2.5 \%$ to $8.7 \%$. Wide ranges of linearity of standard curves were obtained from $0.5 \mathrm{mg} / \mathrm{L}$ to described and applied to 20 toys in Ho Chi Minh $100 \mathrm{mg} / \mathrm{L}$ for DBP, BBP, DEHP and DNOP and city, Vietnam. Phthalates in the sample were extracted in a mixture of acetone and hexane and analyzed by GC-FID. Limits of detection (LOD) and limits of quantification $(L O Q)$ of the analysis method for $D B P, B B P, D E H P$ và DNOP in the $P V C$ plastic were from $0.0011 \%$ to $0.0014 \%$ and from 0.0028 to $0.0046 \%$, respectively. Recoveries of $D B P, B B P, D E H P$ và DNOP in $P V C$ and $P P$ at two spiked concentrations $(0.1 \%$ from $25 \mathrm{mg} / \mathrm{L}$ to $1000 \mathrm{mg} / \mathrm{L}$ for DINP and DIDP with $R^{2}>0.999$. The studied method was a reliable, rapid, easy and cheap method and permitted to determine the restricted phthalates in plastic toys in compliance with European Regulation (No 1907/2006). The method was applied to determine phthalates in 20 toys in HoChiMinh city, Vietnam. Phthalates were found in almost soft PVC toys with high concentrations.
\end{abstract} and $0.01 \%$ ) ranged from $86.6 \%$ to $91.7 \%$ with the

Keywords: GC-FID, GC-MS, phthalates in toy, platiscizer

\section{INTRODUCTION}

Phthalate or phthalate ester is a general term for esterified substances of phthalic acid and alcohol. Phthalate esters are added to plastics to make these materials more flexible and elastic. Phthalates have toxicity such as carcinogenesis, immunization failure or reproduction failure... The high concentrations of phthalates in toys will harm children's health.
The REACH ("Registration, Evaluation, Authorisation and Restriction of Chemicals") Directive (EC No 1907/2006) restricts dibutyl phthalate (DBP), butyl benzyl phthalate (BBP), di-2-ethylhexyl phthalate (DEHP) to $0.1 \%$ in all toys and di-octylphthalate (DNOP), diisononyl phthalate (DINP), and di-isodecyl phthalate (DIDP) to the same percentage in mouthing toys [1]. Moreover, the restricted substances are not 
limited to synthetic resins of which the principal constituent is polyvinyl chloride but have been expanded to other materials that may include plasticizers.

Phthalates in plastic toys can be extracted by different organic solvents and measured by GCFID or GC-MS [2-9]. Recently, in Vietnam, many restricted phthalates with high concentrations were found in plastic toys. Cheap recycled plastic toys manufactured by local companies can also contain phthalates. In this study, 6 restricted phthalates DBP, BBP, DEHP, DNOP, DINP and DIDP were investigated in PVC (polyvinyl chloride) and recycled PP (polypropylene) children's toys in Vietnam.

\section{MATERIALS AND METHODS}

\section{Instrument and operation conditions:}

Table 1. Analytical conditions

\begin{tabular}{|c|c|c|c|}
\hline \multicolumn{2}{|l|}{ GC-FID } & \multicolumn{2}{|l|}{ GC-MS } \\
\hline Model & $\begin{array}{l}\text { GC-FID } 2010 \text { (Shimadzu) } \\
\text { with auto injection }\end{array}$ & Model & $\begin{array}{l}\text { GCMS-QP2010 Ultra } \\
\text { Auto injection: AOC-20i + s }\end{array}$ \\
\hline GC column & $\begin{array}{l}\text { SPB } 5(30 \mathrm{~m} \times 0.25 \mathrm{~mm} \text { I.D., } \\
\left.\mathrm{d}_{\mathrm{f}}=0.25 \mu \mathrm{m}, \text { Supelco }\right)\end{array}$ & GC column & $\begin{array}{l}\text { ZB-5MS (30m x } 0.25 \mathrm{~mm} \text { I.D., } \\
\mathrm{d}_{\mathrm{f}}=0.25 \mu \mathrm{m}, \text { Zebron) }\end{array}$ \\
\hline Column temp. & $\begin{array}{l}100^{\circ} \mathrm{C}-20^{\circ} \mathrm{C} / \mathrm{min}-290^{\circ} \mathrm{C} \\
(6 \mathrm{~min})\end{array}$ & Column temp. & $\begin{array}{l}100^{\circ} \mathrm{C}-20^{\circ} \mathrm{C} / \mathrm{min}-280{ }^{\circ} \mathrm{C}(15 \\
\min )\end{array}$ \\
\hline Carrier gas & $\mathrm{N}_{2}$, velocity: $44 \mathrm{~cm}^{3} / \mathrm{min}$ & Carrier gas & $\begin{array}{l}\text { He (constant linear velocity, } 49 \\
\mathrm{~cm} / \mathrm{sec})\end{array}$ \\
\hline Injection method & Split 1:10 & Injection method & Split: 1:24 \\
\hline Injection volume & $1 \mu \mathrm{L}$ & Injection volume & $1 \mu \mathrm{L}$ \\
\hline Injection temp. & $250^{\circ} \mathrm{C}$ & Injection temp. & $250^{\circ} \mathrm{C}$ \\
\hline Detection temp. & $290^{\circ} \mathrm{C}$ & Ionization & EI \\
\hline & & Ion source temp. & $200^{\circ} \mathrm{C}$ \\
\hline & & Interface temp. & $280^{\circ} \mathrm{C}$ \\
\hline & & Acquisition mode & Scan \\
\hline & & Emission current & $60 \mu \mathrm{A}$ \\
\hline & & Scan range & $\mathrm{m} / \mathrm{z} 45-600$ \\
\hline & & Event time & $0.3 \mathrm{sec}$ \\
\hline & & Scan speed & $2000 \mathrm{u} / \mathrm{s}$ \\
\hline
\end{tabular}




\section{Chemicals and reagents}

Phthalate ester standards ((DBP (99.3\%), DEHP (99.7\%), DNOP (99.5\%)), DINP (> $99 \%$ ), DIDP (> 99\%) and the internal standard benzyl benzoate (BB, analytical grade) were purchased from Sigma-Aldrich, Chemie $\mathrm{GmbH}$, Germany. BBP $(99.9 \%)$ was purchased from Supelco, USA.

Acetone and hexane (for analysis) were obtained from Merk, KGaA, Germany.

\section{Preparation of standard solutions}

Stock standard solutions of 6 phthalate esters (DBP, BBP, DEHP, DNOP, DINP and DIDP) and $\mathrm{BB}$ were prepared separately by dissolving $10 \mathrm{mg}$ of each standard substance in $10 \mathrm{~mL}$ hexane $(1000 \mathrm{mg} / \mathrm{L}(\mathrm{ppm}))$. Three different standard curves were prepared from stock standard solutions. Firstly, for the first four phthalates, working standard solutions (from 0.5 $\mathrm{mg} / \mathrm{L}$ to $100 \mathrm{mg} / \mathrm{L}$ ) for GC-FID analysis containing mixtures of 4 phthalates (DBP, BBP, DEHP and DNOP) were prepared by mixing different volumes of each of the standard solutions, and adjusting the volume to $10 \mathrm{~mL}$ using hexane. Then, for separate working standard solutions of DINP or DIDP (from 25 ppm to $1000 \mathrm{ppm}$ ), different volumes of DINP or DIDP were brought to $10 \mathrm{~mL}$ with hexane.

Limit of detection (LOD) and limit of quantitation (LOQ) of the GC-FID instrument

GC-FID analyses of a standard solution containing a mixture of 4 studied phthalates (DBP, BBP, DEHP, and DNOP), a standard of DINP, a standard of DIDP with low concentrations were performed. LODs and LOQs of the GC-FID instrument of the studied phthalates were the concentrations with the Signal/Noise (S/N) equal 3 or 10 , respectively.

\section{Sample preparation}

To ensure efficient extraction of the phthalates, samples were frozen in liquid nitrogen for several minutes and grated to produce small particles $(<2 \mathrm{~mm})$. Grating was not applied to the soft PVC plastic samples. Soft PVC samples were cut with scissors into pieces of less than $2 \mathrm{~mm}$.

Sample preparation was conducted according to "Japanese Ministry of Health, Labour and Welfare Notification No.336, 2010" [Ministry of Health, Labour, and Welfare Notification No.336, September 6, 2010] [2] with some modifications. In the standard method, sample (1 g) was added $50 \mathrm{~mL}$ of a mixture of acetone: hexane $(3: 7, \mathrm{v} / \mathrm{v})$ and let stand overnight at $40^{\circ} \mathrm{C}$. In this study, sample $(0.5 \mathrm{~g})$ was added only 15 $\mathrm{mL}$ of a mixture of acetone: hexane $(3: 7, \mathrm{v} / \mathrm{v})$ and let stand overnight at room temperature. The sample was centrifugated for 15 minutes at 4000 $\mathrm{rpm}$ and the extract was transferred to a $10-\mathrm{mL}$ volumetric flask and added hexane to $10 \mathrm{~mL}$. Before injecting to GC-FID, the extract was filtered using PTFE filter $(0.45 \mu \mathrm{m})$ and diluted 5 times with hexane. For the GC-MS confirmation, the extract may be diluted over 10 times with hexane.

\section{Recovery study}

PVC blank sample (without studied phthalates) was kindly provided by a laboratory in HoChiMinh city. The PVC blank sample and a raw PP material were used as blank samples for recovery studies of phthalates in PVC and PP matrices.

Blank samples were added standard phthalates at two different concentrations $(0.1 \%$ and $0.01 \%$ ), let stand 2 hours before solvent extraction and GC-FID analysis. 


\section{Analysis of Reference Material (RM)}

RM sample (labelled \#13044) [3] was a children's booklet with a plastic witch inside containg DBP and DINP. The solvent extraction and GC-FID analysis were applied to determine DBP in the RM sample.

\section{Method LOD and LOQ}

Blank PVC sample (0.5 g) was added a mixture of DBP, BBP, DEHP and DNOP at $0.005 \%$ or was added DINP or DIDP at $0.1 \%$ and let stand for 2 hours at room temperature before solvent extraction and GC-FID analysis. LOD and LOQ of the method were the concentrations with the Signal/Noise (S/N) equal 3 and 10, respectively.

\section{Real samples}

A total of 20 plastic children's toy samples (15 soft PVC toys, 5 recycled PP toys) was analyzed for studied phthalates. Samples were focus on soft coloured PVC and hard coloured recycled PP children's toys for children under 3 year olds. PVC toys were bought in supermarkets or markets and recycled PP toys were bought from local manufacturers in HoChiMinh city in 2014 - 2015.

\section{RESULTS AND DISCUSSION}

\section{GC-FID determination}

GC-FID and GC-MS conditions in this study were reported elsewhere [4, 5]. Figure 1 showed the chromatograms of studied phthalate standard solutions by GC-FID in 15 minutes. As DINP and DIDP consist of different isomers, low resolutions of peaks of these phthalates were reported [2-9]. The peak of DNOP are overlapped with peaks of DINP. Peaks of DINP (C9 isomers) are partial overlapped with peaks of DIDP (isomers of C10). Column temperature programs were changed to achieve the separation of DNOP from DINP (data not shown) but the problem sill remained. Therefore, separate standard curves of DINP and DIDP were performed together with the standard curve of a mixture of DBP, BBP, DEHP and DNOP.

The retention time of DNOP is so close to DINP. Therefore, GC-MS confirmation may be used when DNOP is detected in real samples [2].

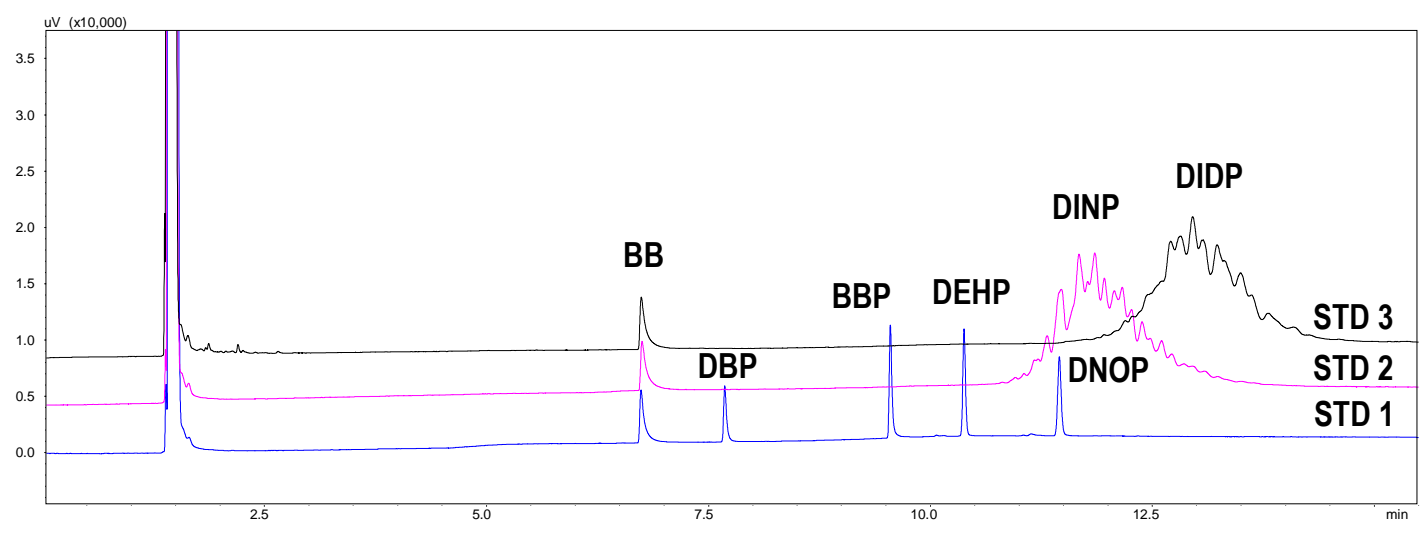

Figure 1. GC-FID chromatograms of phthalate ester standard solutions. 
Table 2. Linearity of phthalate ester calibration curves and LOD and LOQ of the GC-FID instrument and the method

\begin{tabular}{|l|l|l|l|l|}
\hline Phthalate & DBP & BBP & DEHP & DNOP \\
\hline Correlation coefficient $\left(\mathrm{R}^{2}\right)$ & 0.9996 & 0.9997 & 0.9991 & 0.9995 \\
\hline LOD (mg/L) of the GC-FID & 0.13 & 0.10 & 0.10 & 0.12 \\
\hline LOQ (mg/L) of the GC-FID & 0.43 & 0.32 & 0.22 & 0.23 \\
\hline LOD (\%) of the method & 0.0012 & 0.0010 & 0.0014 & 0.0011 \\
\hline LOQ (\%) of the method & 0.0039 & 0.0028 & 0.0046 & 0.0035 \\
\hline
\end{tabular}

\section{Detection limit and linear correlation}

Calibration curves for all of the studied phthalates were linear $\left(\mathrm{R}^{2} \geq 0.999\right)$ in the investigated concentration range $(0.5-100 \mathrm{mg} / \mathrm{L}$ for the first four phthalates (Table 2) and from 25 - $1000 \mathrm{ppm}$ for DINP and DIDP. The LODs for the GC-FID were approximately $0.10 \mathrm{mg} / \mathrm{L}$ and LOQs were from 0.22 to $0.43 \mathrm{mg} / \mathrm{L}$ for the first four phthalates (Table 2). The LODs of DINP and DIDP by GC-FID were approximately 10 ppm and it was not easy to determine LODs due to broad unresolved peaks of many isomers in these phthalates. Analysis of DINP and DIDD was omitted from determinations of restricted phthalates in toys [8].

\section{Sample pretreatment and recovery study}

Firstly, the CPSC-CH-C1001-09.3 pretreatment sample method, prescribed by the US Consumer Product Safety Commission was applied for soft PVC plastic toys [2]. THF (tetrahydrofuran) $(5 \mathrm{~mL})$ followed by hexane $(10$ $\mathrm{mL}$ ) was used for the extraction of restricted phthalates in only $0.050 \mathrm{~g}$ of sample. However, the results of recovery studies were unrepeatable (data not shown) when the mass of sample was increased from $0.050 \mathrm{~g}$ to 0.2 or $0.5 \mathrm{~g}$. Small amounts of the sample $(0.050 \mathrm{~g})$ may not show the representation of the whole analysis sample. In addition, this sample pretreatment was generally applied for PVC plastic when many other plastics may be used in children's toys. Therefore, in this study, sample pretreatment was conducted according to "Japanese Misnistry of Health, Labour and Welfare Notification No.336, 2010" with some minor modifications [2]. The use of only $15 \mathrm{~mL}$ of a mixture of acetone and hexane (3:7) and the extraction at room temperature were advantages of the method.

Recoveries were from $86.6 \%$ to $91.7 \%$ for DBP, BBP, DEHP and DNOP at both spiked concentrations $(0.1 \%$ and $0.01 \%$ (ten times lower than EU Regulation)) with \% RSD from $2 \mathrm{i}$ to 8.7\% (Table 3) in PVC and PP matrices. Recoveries were $92.1(\% \mathrm{RSD}=5.8)$ and 89.7 $(\% \mathrm{RSD}=11)$ for DINP and DIDP, respectively in PVC at the spiked level of $0.1 \%$. DINP and DIDP were not detected in the lower spiked concentration $(0.01 \%)$ in both PVC and PP matrices (Table 3). 
Table 3. \% Recoveries (R) of phthalate esters in PVC and PP

\begin{tabular}{|l|l|l|l|}
\hline Phthalate & R (\% RSD) (spiked 0.1\%) & \multicolumn{2}{l|}{ R (\% RSD) (spiked 0.01\%) } \\
\hline & PVC $(\mathrm{n}=3)$ & PVC $(\mathrm{n}=3)$ & PP $(\mathrm{n}=3)$ \\
\hline DBP & $88.2(6.2)$ & $86.6(4.9)$ & $91.1(5.0)$ \\
\hline BBP & $87.7(3.2)$ & $87.0(7.0)$ & $90.0(7.8)$ \\
\hline DEHP & $90.4(5.7)$ & $91.3(4.6)$ & $87.8(5.4)$ \\
\hline DNOP & $88.7(2.5)$ & $87.0(7.6)$ & $91.7(8.7)$ \\
\hline DINP & $92.1(5.8)$ & - & - \\
\hline DIDP & $89.7(11)$ & - & - \\
\hline
\end{tabular}

\section{LOD and LOQ study of the method}

The LODs of the method were from 0.0010 $0.0014 \%$ for DBP, BBP, DEHP and DNOP (Table 2) in PVC plastic, which all satisfy the limitation requirement of $0.1 \%$. For DINP and DIDP, the LOQ of the method was approximately $0.07 \%$.

\section{Analysis of the RM}

The studied method was applied to the RM sample and DBP were found 0.062 and $0.066 \%$ ( 2 replicates). The true concentration of DBP in the RM sample was $0.072 \%$ (mass/mass) [3]. The studied method was applied to real samples.

\section{Real sample}

The real samples were focused on 2 groups: (1) animal coloured soft PVC plastic children's toys (15 samples) and (2) coloured hard recycled PP children's toys (5 samples including car, cooking or fruit toys). Toys in group 1 were bought in supermarkets or markets in Ho Chi Minh city. They were made in Vietnamese and Chinese and had higher price than toys in group 2 (approximately over 5-folds higher in price).
Toys in group 2 were cheap, recycled PP toys and made by noname local companies (no information of the manufacturers on products). The results of real samples were showed in Table 4.

Because phthalate esters were used as a plastiscizers in PVC, many researches focused on soft PVC toys. In 2000, a total of 72 toys were purchased in 17 countries and many restricted phthalates were found with high concentrations [7]. DEHP was found in $48 \%$ of the analysed PVC toys $(n=72)$ in concentrations of 0.003 $35.5 \%$ followed by DBP $(12.5 \%$ detection frequency with lower levels $0.002-0.18 \%$ ).

In this study, for the soft PVC plastic children's toy group, the predominant phthalates detected were DEHP (8/15 samples) with concentrations from 0.152 to $0.556 \%$ and DBP (5/15 samples) with concentrations from 0.022 to $0.291 \%$. Most of soft PVC studied toys (10/15 samples) contained phthalates with high concentrations (> $0.1 \%$ ), which exceeded the EU Regulation (No 1907/2006).

\section{Trang 84}


Table 4. Real sample

\begin{tabular}{|c|c|c|c|c|c|c|}
\hline Number & Sample name & DBP, $\%$ & BBP, $\%$ & DEHP, \% & $\mathrm{DnOP}, \%$ & Group \\
\hline 1 & Ti14- 1 & - & - & 0.556 & - & \multirow{15}{*}{$\begin{array}{l}\text { (1) Coloured soft } \\
\text { PVC plastic } \\
\text { children's toy }\end{array}$} \\
\hline 2 & Ti14- 2 & 0.115 & - & - & - & \\
\hline 3 & Ti14- 3 & 0.231 & - & - & - & \\
\hline 4 & Ti14- 4 & 0.291 & - & 0.520 & - & \\
\hline 5 & Ti14- 5 & 0.038 & - & - & - & \\
\hline 6 & Ti14- 6 & - & - & - & - & \\
\hline 7 & Ti14- 7 & - & - & 0.197 & - & \\
\hline 8 & Ti14- 8 & - & - & 0.156 & - & \\
\hline 9 & Ti14- 9 & - & - & 0.160 & - & \\
\hline 10 & Ti14- 10 & - & - & 0.154 & - & \\
\hline 11 & To15- 1 & - & - & 0.152 & - & \\
\hline 12 & To15- 2 & 0.022 & - & - & - & \\
\hline 13 & Ho15- 3 & - & - & - & - & \\
\hline 14 & Ho15- 4 & - & - & 0.111 & - & \\
\hline 15 & Ho16-5 & - & - & 0.240 & - & \\
\hline 16 & To15- RaP1 & & & 0.060 & 0.080 & \multirow{5}{*}{$\begin{array}{l}\text { (2) Coloured hard } \\
\text { recycling PP plastic } \\
\text { children's toys }\end{array}$} \\
\hline 17 & To15- RP2 & - & - & - & - & \\
\hline 18 & To- RP3 & - & - & - & - & \\
\hline 19 & A16-1 & - & - & 0.015 & - & \\
\hline 20 & A16-2 & 0.021 & - & - & - & \\
\hline
\end{tabular}

“_": not detected

In developing country, many polymeric materials are recycled and many additives such as plasticizers or flame retardants may be transferred from the recycling materials to the newly manufactured goods. In this study, 5 recycled PP toy samples were analyzed for the phthalates. Concentrations of studied phthalates detected were low (from less than LOD of the method to $0.080 \%$ ). The presence of these phthalates with low concentrations may come from recycling materials or contaminants during manufacturing the toy [8]. Confirmation by GC-MS 


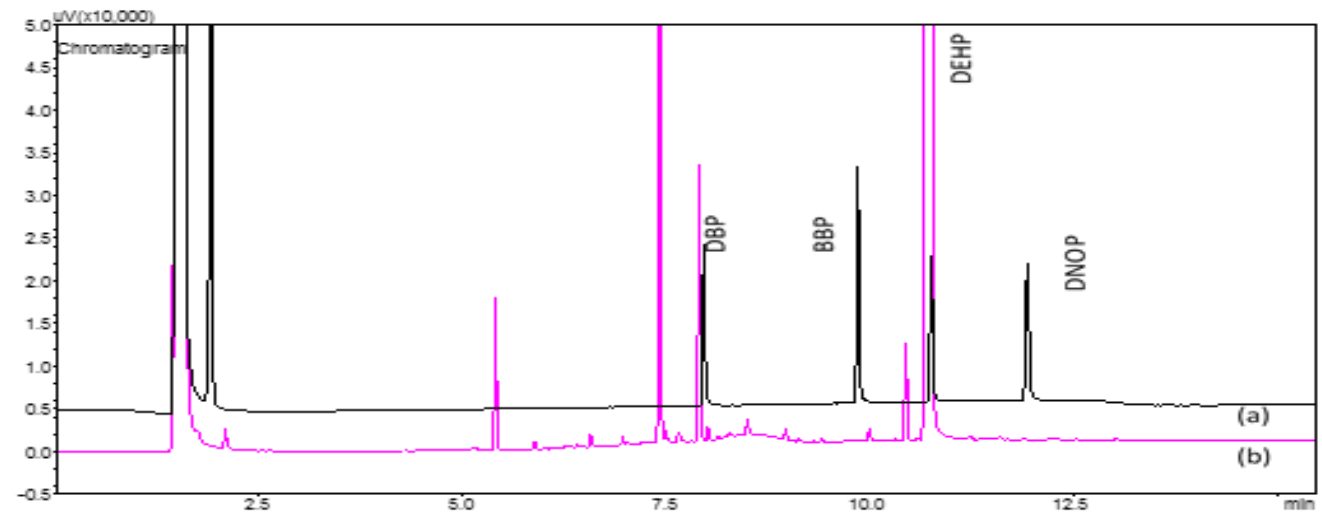

Figure 2. GC-FID chromatograms of phthalate ester in a standard solution (a) and in a PVC-toy sample solution with DBP and DEHP detected (sample Ti14-4) (b).

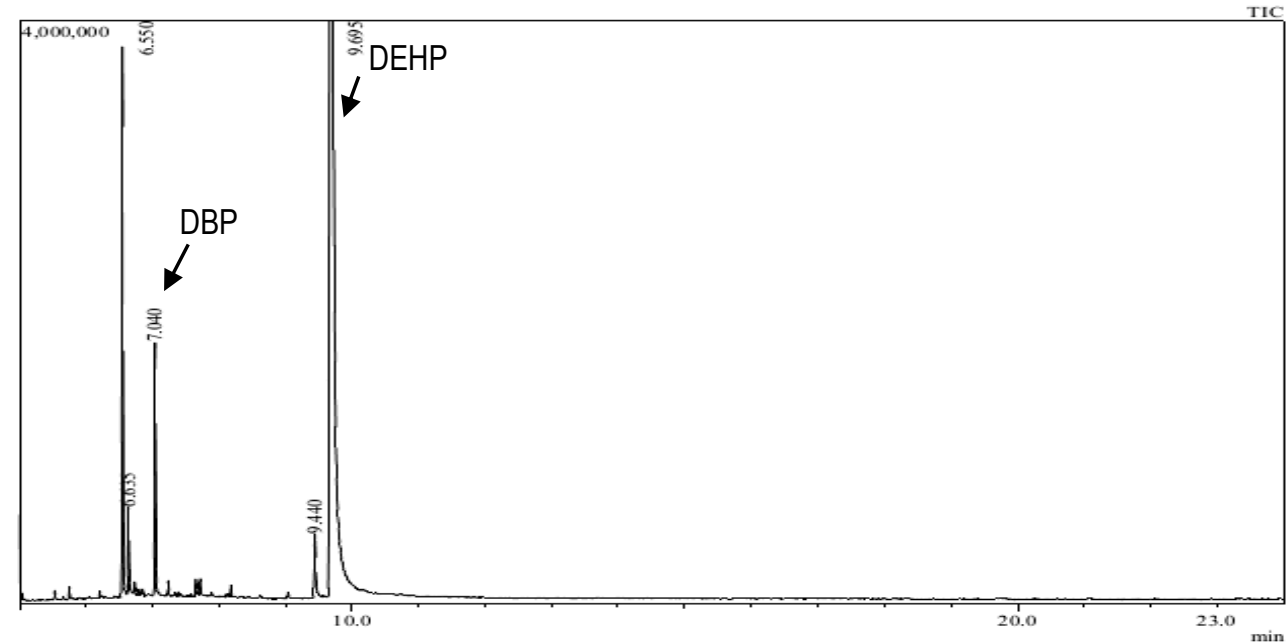

Figure 3. TIC chromatogram of a PVC toy (sample Ti14-4)

Fig. 2 showed the GC-FID chromatograms of studied phthalates in a standard solution (a) and in a PVC toy sample solution (b). Fig. 3 showed the TIC chromatogram obtained from analysis of an extract of a PVC toy (sample Ti14-4) by GCMS. Peaks in the GC-MS chromatogram (Fig. 3) clearly matched the corresponding peaks in the GC-FID chromatogram (Fig. 2 (b)) for the same sample solution (Ti14-4). The mass spectra (Fig. 4 and Fig. 5) showed the presence of DBP (Similarity Index (SI): 98) and DEHP (SI: 96) in the sample. 


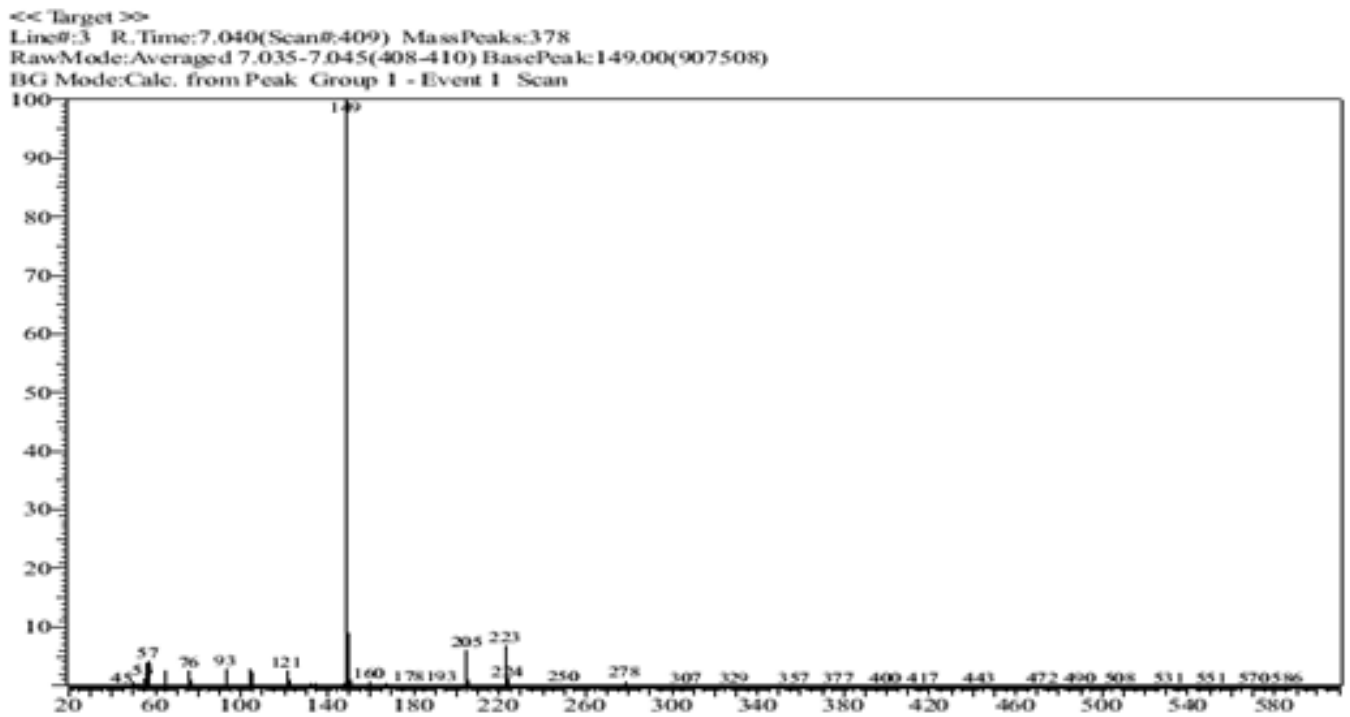

Figure 4. The mass spectra of DBP in PVC toy (sample Ti14-4) at retention time of 7.04 minute

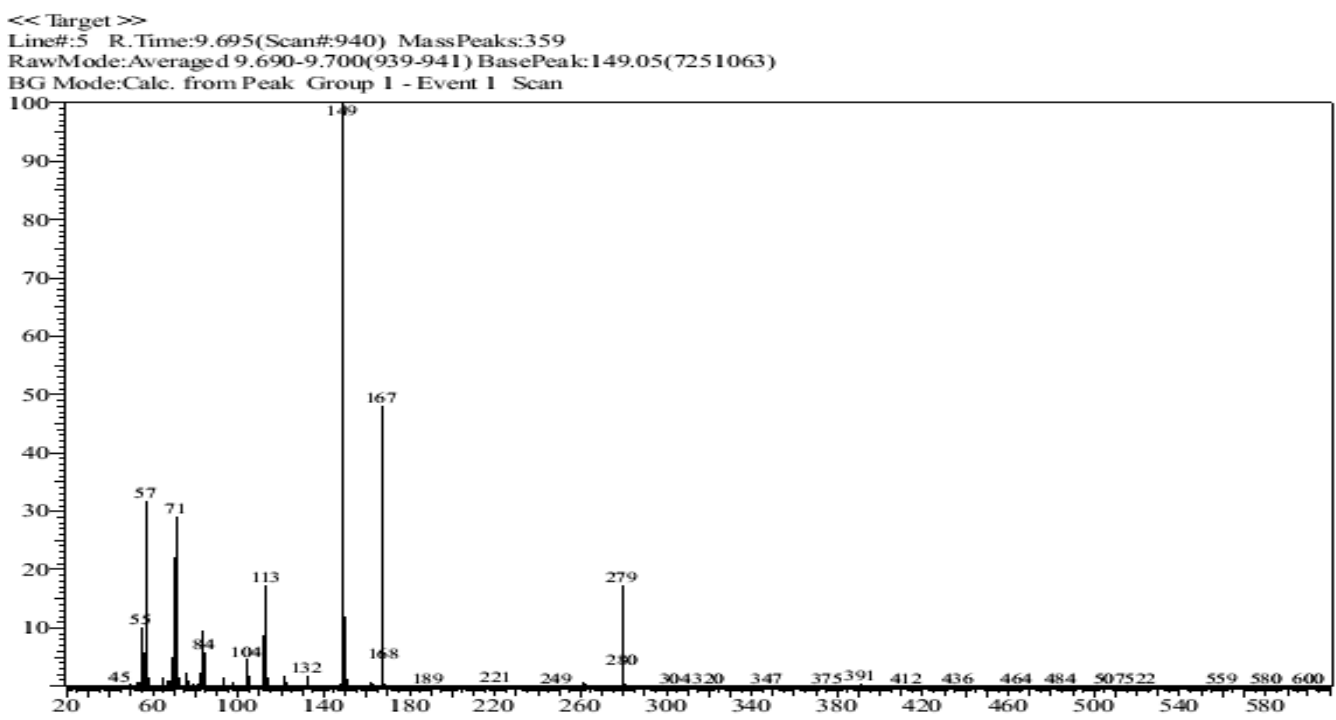

Figure 5. The mass spectra of DEHP in PVC toy (sample Ti14-4) at retention time of 9.69 minute

\section{CONCLUSIONS}

GC-FID analysis with the use of a mixture of acetone and hexane for the pretreatment sample was evaluated for determination of six restricted phthalates in plastics. Recoveries were $>80 \%$ with $\%$ RSD $\leq 11 \%$ for all of the studied phthalates at $0.1 \%$ and $0.01 \%$ in PVC and PP plastic maxtrices. LODs and LOQs of the method were from $0.0011-0.0014 \%$ and from 0.0028 $0.0046 \%$, respectively for DBP, BBP, DEHP and DNOP in PVC plastic. The method was applied to determine restricted phthalates in 20 plastic children's toys in HoChiMinh City, Vietnam. Over 65\% PVC toys (10/15 samples) contained the restricted phthalates with high concentrations 
(> $0.1 \%$ ) and DBP and DEHP were the predominant phthalates. Concentations of studied phthalates were low in recycled PP toys.

\section{ACKNOWLEDGEMENTS}

This research is funded by Ho Chi Minh City University of Technology - VNU-HCM, under grant number T-KTHH-2015-65.

\section{Định lượng phthalate trong đồ chơi nhựa}

- Trần Thị Kiều Anh,

- Lương Trọng Tôn

- Trần Ngọc Hòa

- Phạm Minh Trang

Trường Đại học Bách Khoa - Đại Học Quốc Gia Tp. HCM

\section{TÓM TẮT}

Nghiên cúu trình bày phưong pháp xác định một số phthalate (DBP, BBP, DEHP, DnOP, DINP and DIDP) trong nhụa và íng dụng phân tích phthalate trong 20 mẫu đồ choi nhựa tại thành phố Hồ Chi Minh, Việt Nam. Mẫu được xủ lý bằng kỹ thuật ngâm chiết mẫu với hỗn hơp dung môi acetone và hexane và phthalate nghiên cưu được phân tích bằng phuơng pháp GC-FID. Giới hạn phát hiện (LOD) của phuoong pháp tù $0.0011-0.0014 \%$ và giới hạn định lương (LOQ) của phưong pháp tì $0.0028-0.0046 \%$ cho DBP, BBP, DEHP và DNOP. Độ thu hồi của phuơng pháp tại hai múc nồng độ $(0.1 \%$ và $0.01 \%$ ) trong cả hai nền PVC và PP tù $86.6 \%$ -
$91.7 \%$ vớ $\%$ RSD tù $2.5-8.7 \%$ cho $D B P, B B P$, DEHP và DNOP. Khoảng tuyến tính của đưòng chuẩn (tù̀ $0.5-100 \mathrm{mg} / \mathrm{L}$ cho DBP, BBP, DEHP và DNOP và tù $25-1000 \mathrm{mg} / \mathrm{L}$ cho DINP và $D I D P)$ có hệ số tuoong quan $R^{2}>0.999$. Phuong pháp đơn giản, nhanh, it tốn kém, chính xác và phù hợp để phân tích hàm luợng phthalate trong đồ choi nhựa theo qui định của châu Âu (European Regulation (No 1907/2006)). Phuong pháp nghiên cưu được úng dụng phân tích 20 mẫu đồ choi tại thành phố Hồ Chí Minh. Kết quả phân tích mẫu thực cho thấy hàm lượng phthalate trong đồ choi nhựa PVC mềm cao hơn rất nhiều so với giới hạn cho phép của châu Âu.

Tù khóa: GC-FID, phthalate trong đồ choi, chất hóa dẻo 


\section{REFERENCES}

[1]. REACH - Registration, Evaluation, Authorisation and Restriction of Chemicals, Regulation (Ec) no 1907/2006 of the European Parliament and of the Council of the European Union. Off J Eur Union 49 (L396), 1-849 (2006).

[2] Test Method: CPSC-CH-C1001-09.3 "Standard Operating Procedure for Determination of Phthalates", April, 1, 2010. [http://www.cpsc.gov/about/cpsia/CPSC-CHC1001-09.3.pdf].

[3] "Results of proficiency test phthalates in plastics", April 2013 [http://www.iisnl.com/pdf/iis13P01corrected.pdf .]

[4] Shimadzu Application News No. M261, "Analysis of 6 Phthalate Esters in Polyvinyl Chloride Toys by GC/MS." [http://www.ssi.shimadzu.com/products/literatur e/gcms/m261.pdf].

[5] Shimadzu Application News No. G275, "Analysis of 6 Phthalate Esters in Polyvinyl Chloride Toys by GC-FID." [http://www.ssi.shimadzu.com/products/literatur e/gc/g275.pdf].
[6] Pascal Gimeno, Sebastien Thomas, Claudine Bousquet, Annie-Francoise Maggio, Corinne Civade, Charlotte Brenier, Pierre-Antoine Bonnet, "Identification and quantification of 14 phthalates and 5 non-phthalate plasticizers in PVC medical devices by GC-MS", $J$. Chromatogr. B 949-950, 99-108 (2014).

[7] Rugh Stringer, Iryna Labunska, David Santillo, Paul Johnston, John Siddorn, Angela Stephenson, "Concentrations of phthalate esters and indentification of the other additives in PVC Children's Toys", Environ. Sci. \& Pollut. Res. 7 (1), 27 - 36 (2000).

[8] Alin C. Ionas, Alin C. Dirtu, Tim Anthonissen, Hugo Neels, Adrian Covaci, "Downsides of the recycling process: Harmful organic chemicals in children's toys", Environment International 65, 54-62 (2014).

[9] Lina Huang, Zhongyong Liu, Lezhou Yi, Choghua Liu and Danhua Yang, " Determination of the banned phthalates in PVC plastic of toys by the soxhlet extraction - Gas Chromatography/Mass Spectrometry method", International Journal of Chemistry 3 (2), 169173 (2011). 